\title{
Perancangan Artefak Digital Stiker Whatsapp Bertema Kearifan Lokal dengan Pendekatan ATUMICS
}

\author{
Nina Tri Daniati \\ SMK Negeri 3 Kasihan (SMSR Jogja) \\ ninadaniati7297@gmail.com
}

\begin{abstract}
Communicating is the most basic human need. In daily activities, every human being has the desire to interact with other humans to find out what is happening in the surrounding environment. In prehistoric times before writing, humans wrote by making pictographs. Along with the times, in the era of the internet and smartphones, the use of pictograms has undergone a transformation with the existence of Emoticons and Stickers. Stickers are a form of socio-cultural adaptation to communicate non-verbally with pictographs that have existed since prehistoric times into digital forms in the internet era. Stickers with facial expressions and body gestures are used to express feelings or emotions that are being felt to the other person through the Whatsapp social media chat application. So that Whatsapp Stickers can make communication easier. As a digital artifact, the design of Whatsapp stickers with the theme of local wisdom is analyzed using the ATUMICS method to obtain the ideal arrangement of its basic elements, including: artifacts (Artefact), technique (Technique), utility (utility), material (Material), icon (Icon), concept (Concept), and form (Shape).
\end{abstract}

Keywords: Digital Artefact, ATUMICS, Whatsapp Stickers

\section{PENDAHULUAN}

Sebagai makhluk sosial, berkomunikasi merupakan kebutuhan manusia yang paling mendasar. Setiap manusia selalu memiliki keinginan untuk berinteraksi dengan manusia lain dalam kehidupan sehari-hari untuk mengetahui apa yang terjadi di lingkungan sekitarnya. Hal tersebutlah yang mendorong manusia untuk saling berkomunikasi. Komunikasi merupakan proses penyampaian suatu pesan dari pengirim pesan ke penerima pesan dengan harapan penerima pesan mengerti, memahami, dan memberi respon ke pengirim pesan sehingga tujuan pengirim pesan dapat tercapai dan penerima pesan mudah mengerti, memahami, dan memberi respon ke pengirim pesan. Pengertian tersebut sangat jelas bahwa tujuan komunikasi yang baik yakni tersampaikannya pesan dari pengirim pesan dan pihak penerima pesan memberikan tanggapan.
Dalam kehidupan sehari-hari komunikasi menjadi alat yang sangat penting untuk tercapainya tujuan-tujuan manusia. Tanpa adanya komunikasi manusia tidak akan hidup bermasyarakat. Demikian juga sebaliknya, tanpa masyarakat manusia juga tidak dapat menjalin komunikasi, (Schramm, 1988).

Kebutuhan manusia tergantung pada keadaan sosio historis pada saat manusia itu hidup. Kebutuhan manusia sewaktu zaman praaksara tentunya berbeda dengan manusia pada zaman sekarang. Begitu juga dengan teknik dan pola komunikasi manusia, berbeda antara manusia sekarang dan manusia pada zaman pra-aksara. Penyampaian gagasan mengenai apa yang penting bagi masyarakat telah bertambah, dari sekadar lisan menjadi bentuk tulisan. Manusia pertama yang mengenal tulisan tidak menggunakan huruf, kata-kata, dan tanda baca dalam tulisan mereka. Ribuan 
tahun lalu, mereka "menulis" dengan membuat gambar yang saat ini disebut piktograf. Para pakar mengatakan piktograf tersebut digunakan untuk menyampaikan informasi kepada orang lain. Kata "piktograf" diturunkan dari kata dalam bahasa Inggris "pictograph". Akar kata "pictograph" adalah "pict" dan "graph". "Pict" merupakan kata dalam bahasa Latin untuk picture atau gambar. Sementara "graph" merupakan kata dalam bahasa Yunani yang artinya tulisan. Kadang-kadang piktograf mewakili keseluruhan kata, kadang-kadang hanya mewakili suku-suku kata, atau bagianbagian kata.

Pada era globalisasi, piktogram pertama kali digunakan secara resmi pada Olimpiade di Inggris pada tahun 1948, dan mulai rutin digunakan sejak Olimpiade di Jepang pada tahun 1964. Karena Olimpiade dihadiri oleh berbagai peserta dari berbagai suku bangsa dan bahasa penggunaan piktogram dipandang bisa memudahkan komunikasi. Piktogram lalu digunakan sebagai alat untuk berkomunikasi, menggambarkan cabang-cabang olah raga yang dilombakan. Piktogram ini digunakan pada tiket, sign system, dan lainnya, demikian sehingga peserta dengan mudah dapat mencari tempat kegiatan berlangsung. Piktogram mudah dipahami, karena bentuknya berupaya menyederhanakan, dan tidak sekadar menyimbolkan. Piktogram juga dapat dikatakan sebagai aksara berupa gambar yang mengungkapkan pesan tertentu. Piktogram dianggap mempermudah komunikasi karena dapat menjembatani semua bahasa.

Seiring dengan perkembangan zaman, pada masa awal era internet penggunaan piktogram mengalami transformasi dengan munculnya Emoticon pada September 1982. Emoticon sendiri merupakan kombinasi kata antara 'emotion' yang berarti emosi, dan secara harfiah 'icon' berarti gambar orang suci.
Pembuatan emoticon ini merujuk ke sebuah simbol atau kombinasi dari simbol-simbol yang mengkespresikan wajah manusia. Emoticon adalah tanda yang merepresentasikan ekspresi wajah, mulai dari tersenyum, menangis, tertawa, sedih, marah, dan semacamnya. Untuk membuatnya, pengguna biasa menggunakan kombinasi tanda baca dan emoticon ini hanya berlaku dalam wadah pertukaran pesan berbasis teks.

Pada akhir 1990-an NTT DoCoMo, sebuah perusahaan telekomunikasi asal Jepang, menciptakan Emoji. Nama itu dipakai berdasarkan gabungan kata ' $e$ ' dan ' $m o j i$ ', yang jika diterjemahkan berarti piktograf. Emoji pertama kali hanya berukuran 12 x 12 pixel. Emoji berbasis gambar, yang mewakili berbagai hal, bisa ekspresi wajah, hewan, makanan, buah-buahan, dan sebagainya. Emoji merupakan barisan karakter yang dipakai kebanyakan sistem operasi saat ini dari Unicode. Oleh sebab itu, software yang digunakan pun harus mendukung deretan emoji yang akan dipakai.

Pada tahun 2011 muncul Sticker yang dibuat oleh Jepang yang dipublikasikan melalui aplikasi LINE. Stiker tersebut berupa ilustrasi rinci dari karakter yang mewakili perasaan emosi maupun tindakan yang ingin seseorang lakukan dalam aktivitas perpesanan. Hal ini juga merupakan campuran dari kartun dan emoji Jepang, misal seperti pada tanda senyum. Namun, stiker lebih beragam dari emoticon maupun emoji karena stiker tidak hanya menampilkan ekspresi wajah tetapi juga ekspresi hingga reaksi tubuh sehingga karakternya terkesan lebih kuat. Pada awal 2012, aplikasi dan karakter profil yang ditampilkan dalam koleksi stiker LINE tumbuh dengan pesat dan mendunia. Beberapa aplikasi lain juga ikut menggunakan stiker sebagai cara menyalurkan emosi dalam perpesanan. Salah 
satu aplikasi tersebut yakni Whatsapp. WhatsApp merupakan aplikasi chatting yang biasanya tersedia di smartphone yang memungkinkan penggunanya untuk berbagi pesan dan gambar sehingga bisa digunakan untuk sarana komunikasi verbal maupun nonverbal yang membuat kita semakin menyadari pentingnya penyampaian komunikasi yang berkaitan dengan emosi dan ekspresi. Seiring dengan perkembangan teknologi komunikasi penyampaian emosi dan ekspresi dilakukan melalui sticker chat.

Melalui penjabaran di atas dapat disimpulkan bahwa sticker chat merupakan bentuk adaptasi sosial budaya berkomunikasi nonverbal dengan piktograf yang sudah ada sejak zaman prasejarah menjadi bentuk digital di era internet. Dengan adanya internet yang menjadi media portable dan nirkabel yang kita kenal sebagai mobile, akses komunikasi menjadi semakin mudah. Perkembangan kemutahiran teknologi menyebabkan budaya asing masuk ke negeri kita secara bebas tanpa ada filterisasi. Dengan kemajuan teknologi modern mempercepat akses pengetahuan tentang budaya lain. Perkembangan teknologi yang pesat seperti saat ini semakin mempermudah proses akulturasi budaya terutama pengaruh budaya asing. Dampak yang ditimbulkan ada yang bersifat positif, dan ada yang negatif. Jika kebudayaan asing yang bersifat negatif tersebut merasuki sendi-sendi kehidupan bangsa tanpa diimbangi upaya pelestarian nilai-nilai budaya bangsa, dikhawatirkan Bangsa Indonesia akan kehilangan karakternya. Agar karakter Bangsa Indonesia tetap kukuh, maka kepada generasi penerus bangsa perlu ditanamkan rasa cinta akan kebudayaan lokal.

Indonesia sebagai negara yang kaya akan keanekaragaman budaya, etnis, suku dan ras. Terdapat kurang lebih 389 suku bangsa yang memiliki adat istiadat, bahasa, tata nilai dan budaya yang berbeda-beda satu sama lainnya. Mewujudkan kearifan budaya lokal sebagai tema dalam sebuah perancangan artefak digital yang berupa Stiker Whatsapp dapat menjadi sumber ide dalam penciptaan karya yang tidak terbatas. Selain itu Stiker Whatsapp bertema kearifan lokal menjadi upaya mengintegrasikan nilai-nilai kearifan budaya lokal dalam komunikasi dan interaksi manusia sehari-hari melalui media digital. Hal ini juga merupakan suatu upaya pelestarian budaya dengan mengawinkan kearifan lokal dengan budaya modern digital saat ini. Model adaptasi budaya ini dilakukan dengan pendekatan metode ATUMICS. Melalui metode ATUMICS, Stiker Whatsapp bertema kearifan lokal dianalisis untuk mendapatkan susunan ideal dari elemen dasarnya, yaitu Artefact, Technique, Utility, Material, Icon, Concept dan Shape. Pada akhirnya diharapkan terbentuk produk budaya hasil akulturasi yang dapat mewakili keberadaan produk. Pertanyaan yang dapat diajukan yakni sebagai berikut: Bagaima proses perancangan artefak digital Stiker Whatsapp yang bertema kearifan lokal? Bagaimana pembahasan teori Transforming Tradition dengan metode ATUMICS pada artefak digital Stiker Whatsapp bertema kearifan lokal?

\section{PEMBAHASAN}

\section{Perancangan artefak digital Sticker Whatsapp bertema kearifan lokal}

Pertama kali konsep kearifan lokal (local genius) ini menurut Koentjaraningrat, seperti yang dikutip Kasiyan dan Ismadi, diperkenalkan oleh arkeolog H.G Quaritch Wales dalam tulisannya berjudul "The Making of Greater India: A Study in South-East Asia Culture Change" yang dimuat dalam Journal of the Royal Asiatic Sociaty (1948). Ciri-ciri khas 
atau yang biasa disebut sebagai 'pribumi' itulah, yang oleh Wales diistilahkan 'local genius', yang di dalamnya terkandung makna sebagai 'basic personality of each culture'. Dengan mengacu pendapat Wales mengenai local genius secara luas, dapat diartikan sebagai proses cultural characteristic, yakni perkembangan dari proses fenomenologis ke sifat kognitif, memiliki dasar: (a) Menunjukkan pandangan hidup dan sistem nilai dari masyarakat (orientation); (b) Menggambarkan tanggapan masyarakat terhadap dunia luar (perception); (c) Mewujudkan tingkah laku masyarakat sehari-hari (attitude dan pattern of life); (d) Mewarisi pola kehidupan masyarakat (life style).

Selanjutnya, karakter yang dipilih dalam konteks ini mengambil konsep budaya Jawa sebagai subyek perancangan. Nama tokoh perempuan yakni Ceningsari, sedangkan nama tokoh laki-laki yakni Kelik. Nama tersebut berasal dari kebiasaan orang-orang Jawa jaman dahulu untuk memanggil atau menyebut anakanak mereka.

\section{a. Segmentasi}

1) Demografis

Usia: 12-17 tahun (tween)

Jenis Kelamin:Laki-laki dan Perempuan Pendidikan: Sekolah Menengah

2) Geografis: DIY dan Jawa Tengah

3) Psikologis: Anak remaja yang sudah mengenal persahabatan

4) Perilaku konsumen: Pengguna social media chat Whatsapp

\section{b. Konsep Kreatif}

Desain sticker hendaknya sederhana, menarik, komunikatif, interaktif, ekspresif, dan memiliki tingkat keterbacaan yang baik. Berikut langkah kerja pada perancangan Sticker Whatsapp tersebut:

1) Pra Produksi

Proses pra produksi merupakan langkah awal dalam menyusun sebuah konsep perancangan. Kegiatan yang harus dilakukan meliputi langkah-langkah kerja sebagai berikut:

a) Membuat Desain Properti

Properti yang digunakan oleh karakter sangat menentukan karakteristik dari karakter yang digambarkan. Properti yang digunakan oleh karakter yang diangkat dalam perancangan artefak digital Stiker Whatsapp ini berupa simbol ikonik Budaya Jawa. Properti dari karakter wanita yakni kebaya dan kain batik. Sedangkan properti yang digunakan oleh karakter lakilaki yakni surjan dan blangkon.

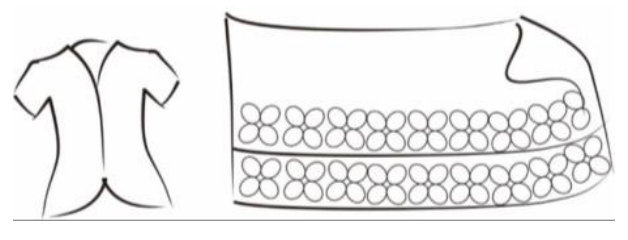

Gambar 1 Desain properti karakter perempuan

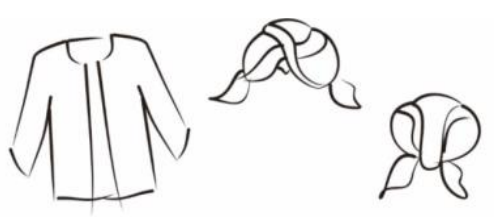

Gambar 2 Desain properti karakter laki-laki

b) Membuat Desain Karakter

Ceningsari adalah seorang gadis bangsawan berusia 10 tahun, berpenampilan sederhana, 
tampilannya feminism, dan pemberani. Kelik adalah seorang anak laki-laki dari dari golongan rakyat jelata, berusia 12 tahun, memiliki sifat penolong dan pemberani.

Proses pembuatan desain karakter yang diangkat dalam perancangan artefak digital Stiker Whatsapp ini menggunakan teknik digital drawing dengan software CorelDraw. Pembuatan sket awal menggunakan Artistic Media Tool.

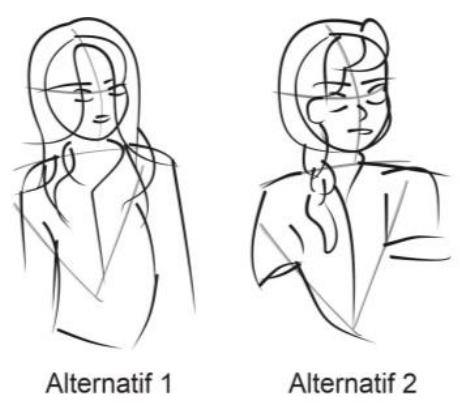

Gambar 3 Alternatif desain karakter Ceningsari

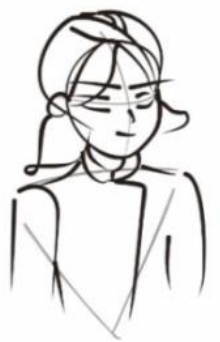

Alternatif 1

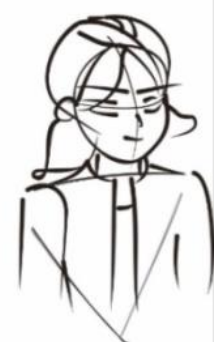

Alternatif 2

Gambar 4 Alternatif desain karakter Kelik

c) Membuat Standar Karakter

Pembuatan desain tampak dari berbagai sudut pandang adalah proses dari pembuatan standar karakter.

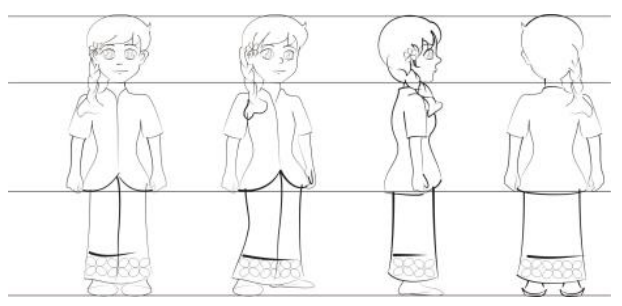

Gambar 5 Desain karakter Ceningsari

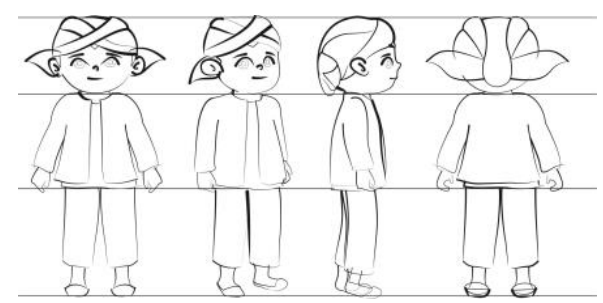

Gambar 6 Desain karakter Kelik

\section{2) Produksi}

Proses Produksi merupakan tindak lanjut dari proses pra produksi. Pada proses produksi ini fokus pada perancangan Sticker Whatsapp, langkah-langkahnya meliputi:

a) Perancangan Layout

Pada proses ini hal yang dilakukan adalah menyiapkan lembar kerja atau kanvas berlatar belakang transparan dengan ukuran 512 x 512 pixel dengan margin antara gambar stiker dan tepi kanvas berukuran 16 pixel. Ukuran ini adalah ukran standar yang sudah ditentukan oleh aplikasi Whatsapp.

b) Ekspresi dan gesture

Eksplorasi ekspresi dan gesture ini membutuhkan kecermatan dan pengamatan yang sangat teliti dalam perancangannya. Menurut Steve Robert ekspresi merupakan tanda pada wajah manusia yang dapat memberikan informasi tentang apa yang sedang dipikirkan oleh si 
pemilik wajah. Manusia memiliki wajah yang dapat membentuk banyak ekspresi (senang, sedih, terkejut, takut, marah, muak, tertarik dan sakit). Mayoritas ekspresi tersebut bersifat universal. Gesture atau body language dapat memberikan petunjuk tentang apa yang karakter pikirkan dan rasakan, apa yang karakter lihat dan perhatikan, serta memperjelas apa yang sedang karakter lakukan. Gesture akan semakin kuat dan menjadi kepribadian karakter jika didukung ekspresi wajah dari karakter tersebut.
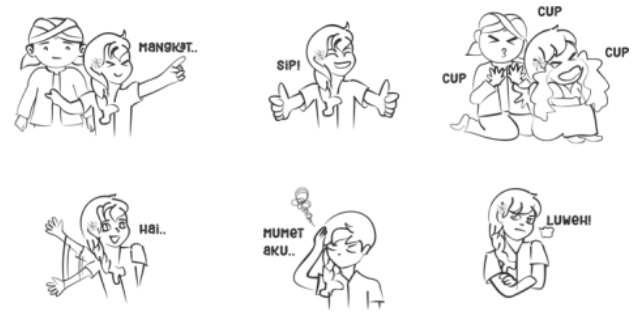

Gambar 7 Explorasi ekspresi dan gesture

\section{c) Coloring}

Proses coloring dilakukan dengan menggunakan software Coreldraw yang dilanjutkan dengan proses menentukan standar warna (color palette). Standar warna yang digunakan pada perancangan desain karakter yang berjudul Ceningsari ini diantaranya adalah sebagai berikut:

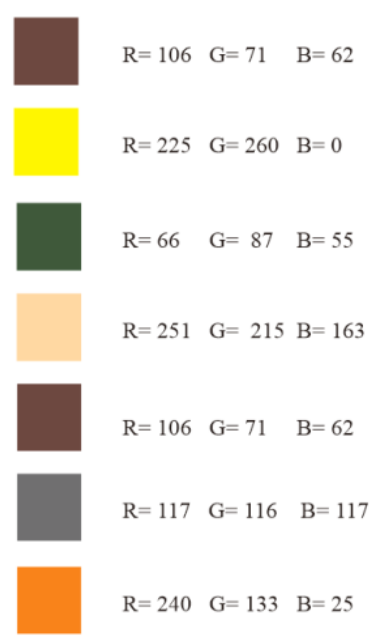

Gambar 8 Standar atau palet warna desain karakter
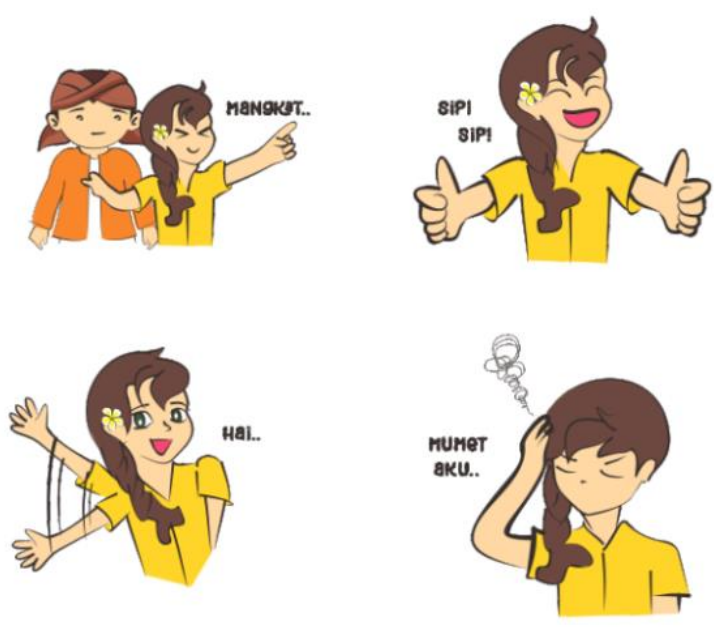

Gambar 9 Hasil Coloring desain Stiker Whatsapp

3) Pasca Produksi

a) Export file stiker ke format .PNG (Portable Network Graphics).

Agar stiker dapat dimanfaatkan dengan optimal sehingga tidak memakan banyak kuota data serta memor perangkat mobile yang dipergunakan maka ukuran file tidak lebih dari $100 \mathrm{~KB}$. 
b) Mentransfer Sticker Whatsapp menjadi bentuk Application Package File (APK).

\section{Transforming Tradition}

Nugraha (2012), menyebutkan bahwa melestarikan budaya tradisi dapat dilakukan dengan mentransformasikan budaya tradisi ke dalam budaya modern. Salah satunya adalah dengan teori Transforming Tradition yang dikembangkan oleh Adhi Nugraha, dan sebagai parameter pengendali untuk melihat bentuk transformasi adalah metode ATUMICS. ATUMICS singkatan dari Artefact-TechniqueUtility-Material-Icon-Concept-Shape. Metode ini digunakan untuk mengkombinasikan beberapa elemen budaya tradisi dengan beberapa beberapa elemen budaya modern pada sebuah desain produk.

Artefact (A), mengacu pada suatu objek yang merupakan pusat dari penelitian ini, yaitu Stiker Whatsapp. Technique (T), teknik menjelaskan mengenai segala jenis pengetahuan teknik, seperti teknik pembuatan, teknik produksi, atau bagaiman akhirnya artefak terbentuk baik melalui proses, sejarah, maupun hal-hal lain yang mempengaruhinya. Teknik berarti juga teknologi, yang mengacu pada semua sarana dan proses dalam mewujudkan memanfaatkan potensi yang ada. Utility ( $\mathrm{U}$ ), pengertian utility (utilitas) digunakan sebagai alat fungsional untuk suatu benda. Material (M), istilah material mengacu pada setiap bentuk fisik dari hal-hal yang dapat dibuat. Icon (I), icon dalam penelitian ini menunjuk kepada bentuk-bentuk simbolis yang mana dapat bersumber dari alam, flora, fauna, geografi, ornamen, dekorasi, warna, mitos, orang, dan artefak. Peran elemen 'ikon' adalah untuk memberikan tanda ikonik dan makna simbolik suatu benda. Concept (C), pemahaman konsep mengacu pada faktor- faktor yang melatarbelakangi terbentuknya suatu objek. Konsep dapat diukur secara kualitatif, seperti kebiasaan, norma, kepercayaan, karakteristik, perasaan, emosi, spiritualitas, nilai-nilai, ideologi, dan budaya. Shape (S), Shape mengacu pada bentuk, performa, dan sifat visual dan fisik dari suatu obyek, termasuk di dalamnya menganalisa ukuran dan proporsi.

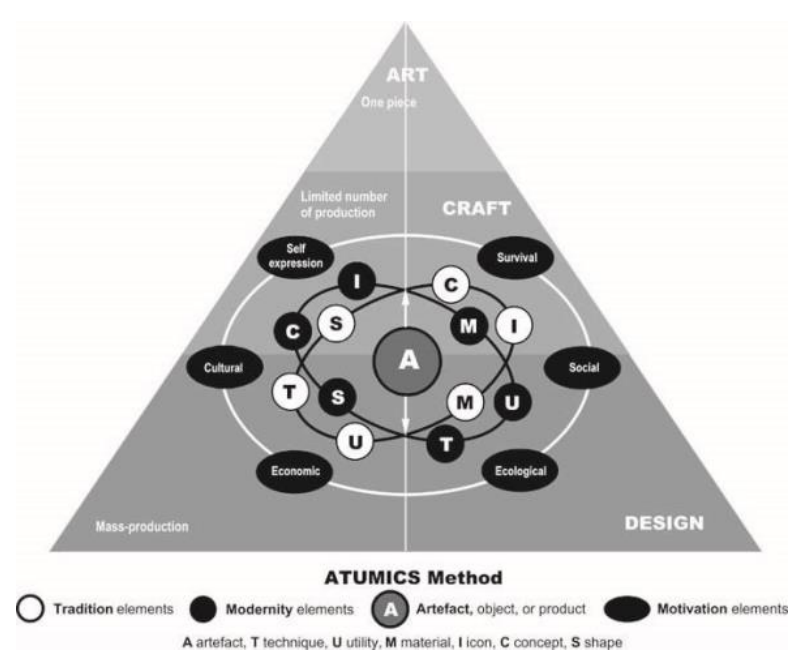

Gambar 10 ATUMICS Method

Melalui metode ATUMICS yang diperlihatkan pada gambar 10. sebuah produk budaya dapat dilihat dari dua level utama tingkat keberadaannya yaitu level mikro dan level makro. Level mikro lebih berkaitan dengan sifat teknis dan penampilan produk, produk dianalisis untuk mendapatkan susunan ideal dari elemen dasarnya, yaitu Artefact, Technique, Utility, Material, Icon, Concept dan Shape. Level makro berkaitan dengan aspekaspek yang lebih luas, yaitu semangat dan motivasi di balik produk yang dihasilkan. Hal ini terkait dengan bagaimana menemukan keseimbangan yang tepat diantara beberapa aspek yang berbeda, budaya, sosial, ekologi, ekonomi, kelangsungan hidup, atau ekspresi diri dalam pembuatan sebuah produk. Dalam 
konsep metode ATUMICS perancangan sebuah produk harus menyatukan kedua level tersebut, yakni level mikro dan level makro.

\section{a. Level Mikro}

Sebagai artefak digital, Stiker Whatsapp berjudul Ceningsari Sticker chat sendiri merupakan bentuk adaptasi sosial budaya berkomunikasi non verbal dengan piktograf yang sudah ada sejak zaman pra-aksara menjadi bentuk digital di era internet. Artefak ini dianalisis menurut elemen dasarnya, yaitu sebagai berikut:

1) Artefact

Mengacu pada suatu objek yang merupakan pusat dari penelitian ini, yaitu Stiker Whatsapp.

2) Technique

Perancangan artefak digital Stiker Whatsapp berjudul Ceningsari menggunakan teknik komputer grafis menggunakan software CorelDraw. Proses selanjutnya mengconvert ke format .webP dengan aplikasi Android Studio.

3) Utility

Kegunaan stiker berupa gambar ekspresi wajah dan gesture tubuh adalah sebagai bentuk komunikasi nonverbal yang digunakan untuk mengungkapkan perasaan atau emosi yang sedang kita rasakan kepada lawan bicara melalui aplikasi social media chat Whatsapp. Penggunaan Stiker Whatsapp dipandang bisa memudahkan komunikasi.

4) Material

Material yang digunakan untuk penyajian Stiker Whatsapp berupa palet warna Mode RGB (Red-GreenBlue), yaitu mode warna pencahayaan (additive color mode) dipakai untuk output devices seperti display monitor.

5) Icon

Ikon budaya Jawa pada artefak digital Stiker Whatsapp berjudul Ceningsari dapat dilihat dari desain karakter dan properti yang digunakan. Karakter yang digunakan adalah seorang gadis Jawa bernama Ceningsari dan pemuda Jawa bernama Kelik. Selain itu simbol ikonik budaya Jawa yang melekat pada kedua karakter tersebut dapat dilihat dari properti yang digunakan berupa pakaian adat Jawa, yaitu kebaya berwarna kuning, dan kain batik bermotif kawung bagi karakter wanita, serta surjan dan blangkon pada karakter laki-laki. Penggunaan warna kuning pada kebaya dan motif kawung pada kain wanita, merupakan simbol ningrat atau bangsawan, sedang pakaian laki-laki menggunakan warna polos dan natural merupakan simbol rakyat jelata.

6) Concept

Konsep merupakan hal yang mendasari perancangan sebuah objek yaitu baik tampilan visualnya atau pada bentuk (shape), ikon (icon) dan kegunaan (utility) sebuah objek/artefak. Konsep perancangan artefak digital Stiker Whatsapp berjudul Ceningsari merupakan usaha mengakulturasikan kearifan lokal dengan budaya berkomunikasi di era digital melalui social media chat.

7) Shape

Unsur shape yang ada pada artefak digital Stiker Whatsapp berjudul Ceningsari adalah bentuk-bentuk ekspresi wajah dan gesture dari 
karakter sticker chat itu sendiri yang berukuran 512 x 512 pixel.

\section{b. Level Makro}

Pada level makro model ATUMICS atau yang biasa dikenal dengan level motivasi akan ditentukan motivasi utama dan motivasi sekunder, dan motivasi lain dari perancangan yang akan dicapai. Pada Stiker Whatsapp berjudul Ceningsari ini motivasi perancangan artefak digital yang akan dicapai dapat dijelaskan sebagai berikut:

1) Motivasi utama berupa motivasi sosial dan budaya. Stiker yang berupa gambar ekspresi wajah dan gesture tubuh digunakan untuk mengekspresikan perasaan atau emosi yang sedang dirasakan kepada lawan bicara melalui aplikasi social media chat Whatsapp. Penggunaan Stiker Whatsapp pun dipandang bisa memudahkan komunikasi. Penggunaan karakter bertema kearifan lokal secara tidak langsung berpartisipasi dalam melestarikan dan mengaktualkan budaya.

2) Motivasi sekunder berupa motivasi ekonomi. Stiker Whatsapp memungkinkan dijadikan sebagai komoditas yang dapat dijual kepada masyarakat.

3) Motivasi lain berupa motivasi ekologi, kelangsungan hidup, dan kreasi ekspresi diri. Pada tingkat ini motivasi lain bukanlah motivasi yang dapat mendasari perancangan artefak digital Stiker Whatsapp.

\section{KESIMPULAN}

Berdasarkan paparan di atas dapat ditarik kesimpulan bahwa perancangan artefak digital
Stiker Whatsapp bertema kearifan lokal melalui proses beberapa tahap. Tahap-tahap tersebut yaitu Pra Produksi, meliputi desain properti dan desain karakter, proses Produksi meliputi perancangan layout, membuat desain ekspresi dan gesture serta melakukan coloring, dan Pasca Produksi meliputi proses export file ke dalam format .PNG dan transfer file ke dalam format Application Package File (APK).

Perancangan artefak digital Stiker Whatsapp bertema kearifan lokal ini dirancang menggunakan pendekatan ATUMICS, meliputi Artefact, berupa Stiker Whatsapp, Technique, menggunakan teknik komputer grafis dengan software CorelDraw, Utility, yakni kegunaan stiker sebagai bentuk komunikasi nonverbal untuk mengungkapkan perasaan atau emosi yang sedang kita rasakan kepada lawan bicara melalui aplikasi social media chat Whatsapp, Material, material yang digunakan untuk penyajian Stiker Whatsapp berupa palet warna Mode RGB (Red-Green-Blue), Icon, ikon budaya Jawa dapat dilihat dari desain karakter dan properti yang digunakan, yaitu seorang gadis dan pemuda yang menggunakan pakaian adat Jawa, Concept, konsep perancangan artefak digital Stiker Whatsapp berjudul Ceningsari sebagai akulturasi kearifan lokal dengan budaya berkomunikasi di era digital melalui social media chat; dan Shape, unsur shape berupa bentuk-bentuk ekspresi wajah dan gesture dari karakter sticker chat itu sendiri yang berukuran 512 x 512 pixel.

\section{KEPUSTAKAAN:}

[1] Eggi, dkk. 2017. Perancangan Ekspresi Dan Gesture Untuk Karakter Animasi 3 Dimensi “Nyi Anteh". Bandung: Program Studi Desain Komunikasi Visual, Fakultas Industri Kreatif, Universitas Telkom. 
[2] Bancroft, Tom. 2006. Creating Characters with Personality. New York : Random House Inc.

[3] It Works. Perbedaan Emoji, Emoticon dan Sticker. Ini Penjelasan Lengkapnya. 2019. https://www.itworks.id/18413/perbedaanemoji-emoticon-dan-stiker-ini-penjelasanlengkapnya.html. Diakses pada tanggal 3 Desember 2020.

[4] Khamadi, K., \& Senoprabowo, A. 2017. Adaptasi Permainan Papan Tradisional ke dalam Permainan Digital dengan Pendekatan Atumics: Studi Kasus Permainan Mul-Mulan. In Seminar Nasional Seni dan Desain 2017 (Vol. 2, pp. 386-393). Surabaya: State University of Surabaya.

[5] Nugraha, A. 2012. Transforming Tradition: a Method for Maintaining Tradition in a Craft and Design Context. Helsinki: Aalto University, School of Arts, Design and Architecture.

[6] Roberts, Steve. 2011. Character Animation Fundamentals. United Kingdom: 1sevier Ltd

[7] Schramm, Wilbur. 1974. How Communication Work, dalam Jean M.Civiklyed Messages. New York: Random House.

[8] Sujud, Slamet. 2013. Prasejarah Indonesia: Tinjauan Kronologi dan Morfologi. SEJARAH DAN BUDAYA, Tahun Ketujuh, Nomor 2, Desember 2013. Malang: Jurusan Sejarah FIS Universitas Negeri Malang.

[9] Wikipedia.Sejarah Komunikasi. https://id.wikipedia.org/wiki/Sejarahkomunikasi. Diakses tanggal 1 Desember 2020 . 